P104 DEVELOPING A PARENT-LED BEFRIENDING SERVICE IN A CHILDREN'S HOSPICE

${ }^{1}$ Dorothy Gillespie; 'Donna Louise Children's Hospice, Stoke- on- Trent, UK

10.1136/bmjspcare-2013-000591.126

In autumn 2010 funding was secured to pilot a bespoke Parent and carer befriending model designed around the specific needs of parents and carers who use the hospice.

Befriending is recognised as a successful model for providing emotional, psychological and practical support. Befriending models are used nationally and internationally to help and support a wide variety of people, children, teenagers, parents.

Aims of Befriending

- Improve the social well-being and psychological health of parents and their families.

- Reduce parental isolation

- Ensure that parents who discover their child has a life shortening illness are supported, through befriending to understand their child's special needs and their own feelings about them.

- Parents become empowered and better able to manage their family's new situation

- Parents are able to communicate better with professionals

Approach Used Five parents were recruited and trained to become Parent and Carer befrienders.

This is a volunteer role and is designed to be flexible to respond to the ever changing needs of the befrienders own unique family situation.

All the recruits undertook a 40 hour training programme to provide them with the knowledge and skills necessary to be a professional parent befriender.

Parents or staff can refer to the service; information is in the family information packs, around the hospice and on the hospice website.

Outcomes Between Jan 2011 and Jan 2012, 11 parents/ carers were befriended.

An average of 40 hours per month of support is being offered to families.

All parents who have used the befriending service reported benefitting from the service and would recommend it to another parent.

Parents rated the befriending service on a scale of $1-10$ the average score was 9.3.

Application to Hospice Practice This service user led/ volunteer based model is transferable across all hospice settings.

- It is a low cost, high return service development in terms of value added for befrienders and the befriended.

\section{P105 EVALUATION OF THE ROLE PLAYED BY PARENT REPRESENTATIVES WITHIN OUR LOCAL PAEDIATRIC PALLIATIVE CARE NETWORK}

Emily Harrop, Bridget Taylor. Helen \& Douglas House Hospices, Oxford, Oxford, UK, Oxford Brookes University, Faculty of Health and Life Sciences, Marston, Oxford, OX3 OFL

\subsection{6/bmjspcare-2013-000591.127}

Background Regional children's palliative care networks play a role in planning and delivering equitable and high standards of care, support and services to children with life-limiting and lifethreatening conditions, and their families ${ }^{1}$. Our local network has had a parent representative since 2010, and is one of only three to do so.

Aim To evaluate the success of the role

Methods We retrospectively reviewed the agenda and minutes of every meeting held between 2010 and 2013 .

Results 15 meetings were held during the study period, and a parent representative was present at 14 . Input made by parent representative included contributions to the work plan; engagement in discussions; offering information; and making specific requests.

Evidence was found that all the questions and requests made by the representatives were addressed. There were also clear signs that the representatives had had a wide influence, on shaping their role within out network, they have also influenced the education delivered by our group and made significant contributions to the ongoing work plan.

Conclusions

1. Do we have regular parental representation? $93 \%$ of meetings had a representative present

2. Do Parent Representatives feel able to speak in the meetings? Only one meeting attended by a representative didn't have a clear contribution. The parent representatives requested a regular dedicated agenda item, since then all meetings show a clear input.

3. Are they heard? $7 / 7$ requests were accommodated and $8 / 8$ questions were addressed either within the meeting or by follow up

4. Do they make a significant contribution? Parent representative lead to a clear development of the parent representative role, as well as a meaningful contribution to virtually every topic addressed by the group.

Applications This study demonstrates an example of good practice that may guide other networks in seeking user engagement. It highlights the impact and value of appropriate parental representation within paediatric palliative care networks. We have shared our experiences with others through Together for Short Lives network summit.

\section{P106 EMPOWERING CHILDREN AND GUARDIANS IN MALAWI}

${ }^{1}$ Kate North, ${ }^{2}$ Joan Marston, ${ }^{3}$ Jean Tauzie, ${ }^{3}$ Lameck Thambo. ${ }^{2}$ International Children's Palliative Care Network, ${ }^{2}$ Help the Hospices, London, UK, ${ }^{3}$ Palliative Care Association of Malawi

10.1136/bmjspcare-2013-000591.128

Introduction The project aims to support the development of children's palliative care services across Malawi. The project aims to integrate children's palliative care into existing service provision in 3 central hospitals.

Aims In this piece of work within the project, the project team aim to empower children and their guardians to be involved in, and inform, decisions that are made about the provision of paediatric palliative care, at local and national level.

Methods Regular empowerment workshops and focus group meetings are held with project beneficiaries (children and their guardians).

An advocacy meeting was between child beneficiaries and the Minister for Health for Malawi.

Learning and Results 
- Empowerment meetings have resulted in patients and guardians feeling more informed about the care they receive and more in control.

- Focus group discussions with beneficiaries have resulted in changing practice at the services themselves.

- Empowerment meetings have been most successful when participants identify their own key concerns and have the space to explore solutions with others.

- Experience sharing and testimonies have played a great part in encouraging and learning from each other.

- The workshop with the project beneficiaries and Minister for Health allowed policy makers to hear first hand the experience of those living with life-limiting illnesses resulted in the minister pledging support to children's palliative care in Malawi.

The project is of interest to others who are working to support development of children's palliative care. We would like to share our approach and learning with others, and to encourage discussion about participation and empowerment in any palliative care setting.

\section{P107 WHO HAS DREAMS FULFILLED AT END OF LIFE? AN AUDIT OF A DREAM FULFILMENT ORGANISATION FOR CHILDREN AND YOUNG PEOPLE}

1,2 Jayne Galinsky, ${ }^{2}$ Liz Forbat, ${ }^{2}$ Emma France, ${ }^{1}$ Jane White. ${ }^{1}$ Cancer Care Research Centre, University of Stirling, Scotland, ${ }^{2}$ Dreams Come True - children and young people's charity

\subsection{6/bmjspcare-2013-000591.129}

Dream fulfilment provides a positive focus, hope and a sense of future for children and young people whose lives may be filled with hospital visits, pain or worry. This paper will present the results of an audit of a dream fulfilment charity's database. The audit systematically analyses user demographics to find out more about who uses charities such as these. This project fits with the strategic exercise conducted by the NHS in England to 'map' palliative care services across England so that both health professionals and the public can see what services are, and where they are available.

The data reported in this paper are drawn from Dreams Come True's records of children and young people with life limiting and long term conditions and their families, and the dreams that they have had.

Descriptive statistics are used to summarise the clinical and socio-demographic characteristics of the children/ families who have used the charity's services over the last five years. Results highlight the range of health conditions that children who use the charity have, as well as reporting on other factors such as the child's age, family size, gender and the type of dream requested. Analysis also suggests gaps in service reach which may reflect the unmet need in the sector as a whole.

Results will be of interest to health care professionals working in the fields of paediatric palliative care, and care of children with long term conditions, as well as to other dream fulfilment charities. The audit's findings have implications for referring organisations, such as hospices, and potential lessons for the adult sector.

\section{P108 THE TRANSITION TASKFORCE - MAKING THE DIFFERENCE FOR YOUNG PEOPLE WITH LIFE-LIMITING CONDITIONS}

\section{David Strudley, Lizzie Chambers. Together for Short Lives Transition Taskforce}

\subsection{6/bmjspcare-2013-000591.130}

Background Context Recent research from Leeds University shows there is a far greater number of young people who would benefit from palliative care, than previously believed. The study shows that the number of young people aged 16-19 with lifelimiting conditions is growing and has increased by $44.8 \%$ over the past 10 years. Services, including hospices, do not currently serve this growing population of young people and their families well.

Aim The project aims to make a real and tangible difference to the experience of young people with life-limiting conditions as they make the transition to adult services.

Approach Used Building on the growing evidence base, in particular findings from the STEPP Project, the project will adopt a two-pronged action-focussed approach to putting research and policy into practice:

- At national level, developing guidance, raising awareness, providing training and support for adult providers ensuring that the 'push' from children's services is balanced by a 'pull' from adult services.

- At local/regional level, supporting the development of services and partnerships between children's and adult services, so that the research and good practice that exists is implemented on the ground and disseminated nationally.

Outcomes The outcomes of the project will be that:

- young people and their families have more choice and control to make informed decisions about their care

- children's and adult services in the voluntary and statutory sector work together to support young people through transition

- wider services, such as housing, education, employment and independent living provide services that meet the needs of young people with life-limiting conditions

Application to Hospice Practice Adult hospice services can learn how to plan and deliver the care that young adults with life-limiting conditions need.

\section{P109 TRANSITION IN PALLIATIVE CARE STUDY DAY SERIES}

${ }^{1}$ Victoria Lidstone, ${ }^{2}$ Stephanie Sivell, ${ }^{3}$ Mark Taubert, ${ }^{4}$ Catherine Thompson, ${ }^{2}$ Annmarie Nelson. ${ }^{1}$ Cardiff and Vale University Health Board, ${ }^{2}$ Marie Curie Palliative Care Research Centre, Cardiff University School of Medicine, Cardiff, UK, ${ }^{3}$ Marie Curie Hospice, Cardiff and the Vale, ${ }^{4} T$ Hafan

\subsection{6/bmjspcare-2013-000591.13}

Background / Context Medical advances have led to more children with life-limiting conditions surviving into adulthood with an increasing number accessing adult Specialist Palliative Care (SPC) services. These young adults often have conditions unfamiliar to adult SPC professionals, who may be inexperienced in caring for their complex needs. Results from previous research carried out by the same team, identified a need for a training/ education programme for adult SPC professionals and provided recommendations regarding content and delivery.

Aim To develop a training programme to help up skill and build confidence in adult SPC professionals regarding the care of young adults with life-limiting conditions. 